\title{
Gametophytic self-incompatibility re-examined: a reply
}

\author{
M. J. Lawrence, D. F. Marshall, \\ V. E. Curtis and C. H. Fearon
}

Department of Genetics, University of Birmingham, Birmingham B15 2TT.

In principle, as has long been known, there are two ways by which the stigmas or styles of the flowers of selfincompatible species could discriminate between incompatible and compatible pollen, for either the growth of the former would be inhibited (the oppositional hypothesis) or that of the latter stimulated (the complementary hypothesis). In practice, however, the genetics of gametophytic systems all but rules out the second possibility, largely because of the number of alleles involved. Furthermore, nearly all of the more recent evidence concerning the behaviour of pollen on the stigma or style, both of the observational and the biochemical kind, is inconsistent with the complementary hypothesis. In a recent paper, however, Mulcahy and Mulcahy (1983) have argued that the oppositional hypothesis is unable to provide a satisfactory explanation of several more recent observations concerning gametophytic systems and have proposed a new, multigenic model that is based on the complementary hypothesis of discrimination. A review of the evidence regarded by the Mulcahys as inconsistent with the oppositional hypothesis reveals that this is either not relevant to the question of discrimination or has been misunderstood. Furthermore, the Mulcahys' model is inconsistent with the empirical evidence concerning multi-locus systems and is formally consistent with one-locus systems only if it is assumed that the constituent loci of the $\boldsymbol{S}$-supergene are very tightly or completely linked, an assumption not made by the Mulcahys. Their perception of the evidence, therefore, is incomplete and their model ill-founded. Hence the Mulcahys' claim to have put forward a new model of gametophytic self-incompatibility which is consistent with the empirical evidence cannot be sustained.

\section{INTRODUCTION}

In principle, there are two ways by which stigmas or styles of the flowers of self-incompatible species could discriminate between incompatible and compatible pollen, for either the growth of the former could be positively inhibited, the oppositional hypothesis; or the growth of the latter could be positively stimulated, the complementary hypothesis. In practice, however, as Lewis (1954) has pointed out, the genetics of all but two of the systems of self-incompatibility that are known in the flowering plants virtually rules out the second possibility. Consider, for example, the one locus, multi-allelic system where control of the pollen phenotype is gametophytic that was first described by East and Mangelsdorf (1925) in Nicotiana alata and $N$. forgetiana. Each plant of a species with this system, being heterozygous for the $S$-gene, must produce two pollen and (at least) two stylar recognition substances. Then if a complementary stimulation between unlike gene products is the cause of incompatibility, in the absence of dominance the growth of $S_{1}$ pollen of an $S_{1} S_{2}$ individual would be stimulated by the $S_{2}$ stylar substance and that of the $S_{2}$ pollen would be correspondingly stimulated by the $S_{1}$ stylar substance; that is, the plant would be self-compatible. On the oppositional hypothesis, on the other hand, the growth of $S_{1}$ pollen is inhibited by the $S_{1}$ stylar substance and that of $S_{2}$ pollen by the $S_{2}$ stylar substance, giving the observed self-incompatibility. An additional difficulty with the complementary hypothesis is that the stigmas or styles of each individual would need to produce a complementary substance for every allele present in the population that is not carried by itself; since there appear to be 40 to 50 different $S$-alleles in both the Oenothera organensis (Emerson 1939, 1940) and Papaver rhoeas populations (Campbell and Lawrence, $1981 b$; Lawrence and O'Donnell, 1981), this is improbable. The same arguments apply to the two-locus systems of the grasses (Hayman, 1956; Lundqvist, 1956) and to the four-locus systems recently discovered in Ranunculus acris (Østerbye, 1975) and Beta vulgaris (Larsen, 1977), except that in these systems the recognition substances are the products of two or four genes, respectively; and these arguments 
also apply to the homomorphic multi-allelic systems in which there is sporophytic control of the pollen phenotype (Hughes and Babcock, 1950; Gerstel, 1950), because many allelic combinations display independent action in the stigma and sometimes in the pollen also. It is thus difficult to see how a mechanism of complementary stimulation of compatible pollen could work in species with homomorphic systems of self-incompatibility. The oppositional hypothesis, first proposed by Prell (1921), on the other hand, provides a consistent and parsimonious explanation of a considerable body of empirical evidence.

Now these arguments are hardly new, for they have appeared to provide a satisfactory basis for an understanding of how incompatibility systems work for at least thirty years. In a recent paper, however, Mulcahy and Mulcahy (1983) claim that the oppositional hypothesis is unable to provide a satisfactory explanation of several more recent observations concerning gametophytic systems and have proposed a new multigenic model that is based on the complementary hypothesis. If the Mulcahys are right, we should have to undertake a major revision of our understanding of incompatibility systems. It is, therefore, a matter of some importance to examine their arguments for supposing that such a revision is necessary and to ask whether the complementary model they have proposed is capable, as they claim, of providing a better explanation of the very considerable body of empirical evidence than the oppositional hypothesis.

\section{EVIDENCE CITED AS INCONSISTENT}

WITH THE OPPOSITIONAL HYPOTHESIS

The Mulcahys present five pieces of evidence which, they claim, cannot be explained by the oppositional hypothesis of self-incompatibility.

The first of these pieces of evidence comes from Larsen's work on the genetics of self-incompatibility in Beta vulgaris in which he has shown that there is a relationship between the heterozygosity of a plant with respect to the incompatibility genes and its pseudo self-compatibility (Larsen 1975, $1977 a$; not $1977 b, 1978 a, 1978 b, 1978 c$ as cited in the Mulcahys' paper). Thus in one experiment (Larsen 1975), he found that whereas 15 out of 21 quadruple heterozygotes set a small amount of seed when selfed, only one other plant set any seed when selfed in a family of 139 plants, these other plants being either single, double or triple heterozygotes. In two further experiments carried out in the hot summers of 1975 and 1976, Larsen (1977a) observed an approximately linear relationship between the proportion of plants that set some seed when selfed and their heterozygosity such that single, double, triple and quadruple heterozygotes gave proportions of $10,35,73$ and 91 per cent respectively. These observations suggest that there is a negative relationship between the strength of the incompatibility reaction and level of heterozygosity which is fully revealed only at high ambient temperatures. Lundqvist (1958) has observed a similar relationship between pseudo self-compatibility and level of heterozygosity in inbred families of rye. Larsen (1977a) suggests that this relationship in beet might be due to competition for a precursor of stylar recognition substances. Thus, assuming that the incompatibility mechanism in B. vulgaris is similar to that of the grasses, whereas only two specificities will be produced in the styles of single heterozygotes, four, eight and sixteen such specificities will be produced in the styleds of double, triple and quadruple heterozygotes respectively. Hence, if there is competition for a precursor, quadruple heterozygotes should be the most vulnerable to this effect. However, while this hypothesis provides an explanation of the apparent dilution of the strength of the incompatibility reaction that is observed, it says nothing about the nature of this reaction. It is not obvious to us, therefore, why this evidence should be regarded as inconsistent with the oppositional hypothesis.

The second piece of evidence comes from the experiments of Nettancourt et al., (1971) in which they found a new functional $S$-allele among the inbred descendants of a self-incompatible $S_{1} S_{2}$ individual of Lycoperisicum peruvianum. This new allele, found several times, was always the same, $S_{3}$, and was usually first detected in the styles, but not the pollen of $S_{2} S_{2}$ homozygotes, implying that $S_{3}$ had originated as a stylar-part mutation from $S_{2}$. The new allele was transmitted in crosses between the plants in which it was first detected and various tester stocks as a single factor, allelic to the $S$-locus and was expressed in the progeny of these crosses both in the pollen and the style. When backcrosses were made between plants containing the new allele $\left(S_{1} S_{3}\right.$ or $\left.S_{2} S_{3}\right)$ and the original parent $\left(S_{1} S_{2}\right), S_{3}$ occasionally reverted to $S_{2}$. In later experiments, it was claimed that five new specificities had been detected in the styles (though not the pollen) of the inbred descendants of $S_{1} S_{2}$ individuals; and in some cases, the styles of these plants apparently expressed more than two specificities, one plant expressing no less than five such specificities (Gastel and Nettancourt, 
1975; not Nettancourt et al., 1975 as cited by the Mulcahys).

It is difficult to know what to make of these results, particularly because it has not always been possible to repeat them. Thus Sree Ramulu (1982a) was unable to confirm the results of Nettancourt et al., (1971) when $S_{1}$ and $S_{2}$ were put into different genetic backgrounds; and he also failed to confirm Gastel and Nettancourt's (1975) findings when the eight plants in question were subjected to a more thorough analysis. On the other hand, Sree Ramulu ( $1982 b)$ did detect mutations and reversions in $L$. peruvianum plants regenerated from anther, but not from stem, cultures. The other difficulty with these results is explaining them. In view of the fact that Nettancourt et al., (1971) obtained a high proportion of their new mutations from $S_{2} S_{2}$ individuals, a recombinational origin for $S_{3}$ seems improbable; and the notion that every member of the population carries on its chromosomes a silent copy of each of the $S$-alleles segregating in the population and that, on occasion, one of these becomes activated appears even less likely (Nettancourt, 1977). Hence no satisfactory explanation of the results obtained in these experiments has yet been suggested. It is clear, therefore, that this evidence cannot be regarded as inconsistent (or, for that matter, consistent) with the oppositional hypothesis of $S$-gene action, or, indeed any other hypothesis.

The third piece of evidence regarded by the Mulcahys as unexplained by the oppositional hypothesis is that the incompatibility gene is difficult to map. This is simply not true. The Mulcahys appear to have misinterpreted an unfortunate statement by Nettancourt (1977) which says that "In homomorphic systems, cases of linkage to the $S$-locus are extremely rare". Since Nettancourt goes on to list seven such cases, we disagree with this statement too. The ease with which it is possible to detect linkage between the $S$-gene and others will depend, among other things, on the scale of the investigation and on the availability of other genetical markers. On the first point, it is surely no accident that four of the seven cases mentioned in Nettancourt's book concern the much studied species, Nicotiana sanderae (Brieger and Mangelsdorf, 1926), Oenothera organensis (Emerson, 1941), Trifolium pratense (Denward, 1963) and Brassica oleracea (Thompson and Taylor, 1965). Second, while, in the past, the detection of linkage between the $S$-gene and others may have been hindered by a shortage of suitable genetical markers, this is no longer the case, since the genes of the ubiquitous enzyme polymorphisms that can be detected by gel electrophoresis can be used for this purpose. For example, we found no difficulty in detecting and estimating linkage between $S$ and a gene that codes for phosphoglucoisomerase in Lolium perenne and L. multiflorum (Cornish, Hayward and Lawrence, 1980; Fearon, Hayward and Lawrence, 1983); and Labroche, Poirier-Hamon and Pernes (1983) have shown that the $S$-gene in Nicotiana alata is linked to two genes which code for leaf peroxidases. The incompatibility genes, therefore, are no more difficult to map than other genes.

The fourth piece of evidence is based, unfortunately, on a misunderstanding of the population genetics of the homomorphic, gametophytic selfincompatibility polymorphisms. The Mulcahys state that "whenever natural populations have been surveyed for incompatibility alleles, it is generally found that a high proportion of all plants carry two incompatibility alleles and each of these is found in no other plant". First, with a one locus system all plants in a population of diploids must carry two alleles and, because of the genetics of self-incompatibility, these must be different; observations by Emerson (1939) on the Oenothera organensis population and our own on populations of Papaver rhoeas (Campbell and Lawrence, $1981 b$; Lawrence and O'Donnell, 1981) confirm this expectation. Homozygotes will occur only if the self-incompatibility mechanism breaks down. Second, both Emerson and ourselves found that most of the $S$-alleles occurred more than once in our samples; for example, only 7 alleles out of a total of 28 found in a sample of 37 plants from the Oenothera population occurred once, the remaining 21 occurring at least twice, three of which occurred no less than five times apiece. The Mulcahys also appear to be unaware that the Oenothera problem (Wright, 1939) of how 45 alleles could be maintained in a small population has been solved, now that it seems likely that the population consists of 5000 , rather than 500 plants, which, as Wright showed is the size of population required to maintain this number of alleles at equilibrium (Levin, Ritter and Ellstrand, 1979; Campbell and Lawrence, 1981 $a$ ).

The fifth and final piece of evidence that the Mulcahys regard as inconsistent with the oppositional hypothesis is a report "that androgenic haploids of self-incompatible Lolium perenne, after chromosome doubling, show a high frequency of self-compatible individuals". However, the paper cited (Hoffman and Wenzel, 1981) concerns rye (Secale cereale), not ryegrass (Lolium perenne) and contains the following statement in the discussion section. "Regarding the analysis of the androgenetic" (i.e., dihaploid) "lines we have 
shown that the anther culture passage delivered self-compatible inbred lines, when initiated from heterozygous self-compatible $\mathrm{F}_{1}$ anther donor hybrids" (the italics are ours). There is, thus, no mention in Hoffman and Wenzel's paper of selfcompatible dihaploids being obtained from selfincompatible diploids even in rye. We are unable to understand how such a gross misrepresentation of this evidence could have occurred.

Hence, in our view, none of these five pieces of evidence can be regarded as inconsistent with the oppositional hypothesis. It follows, therefore, that the Mulcahys have failed to demonstrate the need for a new model of self-incompability. Nevertheless, it is worth examining their model to see whether it is capable of explaining the very considerable amount of empirical evidence concerning gametophytic systems of self-incompatibility more economically than the oppositional model.

\section{THE MODEL}

In the Mulcahys' own words: "The model, called the heterosis model of self-incompatibility, is based on the assumption that if pollen and style carry dissimilar alleles, there will be heterotic interactions between them and pollen tube growth rate will increase. If the style is homozygous for a deleterious recessive allele and the pollen carries the same allele, pollen tube growth rate will be reduced. The actual growth rate of the pollen tube will be the sum of all pollen-style interactions". Their model, therefore, has two key features; first that the $S$-gene is a supergene composed of a group of linked loci and second, that compatibility occurs when the growth of pollen tubes is stimulated. Each supergene contains one dominant gene; all the rest are assumed to be deleterious recessives. Hence, $S_{1}$ is Abcd--, $S_{2}$ is a Bcd--, $S_{3}$ is abCd--, and so on; and the phenotypes of $S_{1} S_{2}$ and $S_{1} S_{3}$ styles, for example, are ABcd-- and AbCd--, respectively. The Mulcahys quantify the four kinds of interaction (recognition events) that can occur between pollen and style with respect to each gene in the complex in the following way:

\begin{tabular}{llc}
$\begin{array}{l}\text { Stylar } \\
\text { phenotype }\end{array}$ & $\begin{array}{l}\text { Pollen } \\
\text { phenotype }\end{array}$ & Score \\
A & A & 0 \\
A & a & +1 \\
a & A & +1 \\
a & a & -1 \\
\hline
\end{tabular}

Table 1. Interactions between pollen and stylar phenotypes on the Mulcahys' model. Compatible combinations are $\geqq 1$, incompatible combinations are $\leqq 0$

\begin{tabular}{|c|c|c|c|c|}
\hline \multicolumn{2}{|c|}{ Stylar } & $\begin{array}{l}S_{1} \\
\mathrm{~A} \\
\mathrm{~b} \\
\mathrm{c}\end{array}$ & $\begin{array}{c}\text { Polle } \\
S_{2} \\
\mathrm{a} \\
\mathrm{B} \\
\mathrm{c}\end{array}$ & $\begin{array}{l}S_{3} \\
\mathrm{a} \\
\mathrm{b} \\
\mathrm{c}\end{array}$ \\
\hline Genotype & Phenotype & & & \\
\hline$S_{1} S_{2}$ & $A B C$ & 0 & 0 & 3 \\
\hline$S_{1} S_{3}$ & A b C & 0 & 3 & 0 \\
\hline$S_{2} S_{3}$ & a $B C$ & 3 & 0 & 0 \\
\hline$S_{1} S_{1}$ & $A b c$ & -2 & 1 & 1 \\
\hline$S_{2} S_{2}$ & $\mathrm{a} B \mathrm{c}$ & 1 & -2 & 1 \\
\hline$S_{3} S_{3}$ & $\mathrm{a} b \mathrm{C}$ & 1 & 1 & -2 \\
\hline
\end{tabular}

These scores are then summed over loci to give an overall score for the interaction in question, which, in turn, indicates the relative growth rate of the pollen. Sums for the case where the supergene consists of only three loci are shown in table 1 . The Mulcahys conclude the introduction of their model with the following paragraph:

"The heart of the heterosis model is our assumption that the pollen tube growth rate will be proportional to the sum of all such pollen-style interactions. Incompatible pollinations are due, not to specific inhibitory molecules, but rather to pollen tube growth being too slow to allow fertilisation before floral abscission."

There are four points that we wish to make about this model. First, we note that it is the presence of a single dominant gene in the supergene complex that determines its specificity. It follows, therefore, that there must be as many loci in the supergene as there are $S$-alleles in the species, which judging by the number of alleles in Oe. organensis and $P$. rhoeas populations, suggests a minimum of 40 to 50 loci; this seems unlikely. Furthermore, as mentioned earlier, each of these genes would need to produce a specific recognition substance; such an unwieldly system seems unlikely. Indeed, the only advantage that the Mulcahys' model has over the complementary model mentioned earlier is that, because of dominance in the style, plants are self-incompatible.

Second, though the Mulcahys are clearly not aware of this, the constituent loci of each supergene must be very tightly, if not completely linked in thier inheritance, for their model to be workable. 
Thus, following recombination, supergenes could contain more than one dominant gene, flouting the requirement that each supergene should have only one, and successive recombinational events will generate plants that are self-compatible on the Mulcahys' scoring system. In short the only way that the Mulchay's model can satisfactorily account for the very considerable body of empirical evidence concerning one-locus systems of self-incompatibility is to assume that the constituent genes of the supergenes recombine at a frequency not much above the mutation rate of the $S$-locus, which is, of course, very low (Lewis 1948, 1949, 1951). It follows, therefore that there is little to be gained, in a practical sense, by supposing that the $S$-gene is composed of a large number of loci rather than one.

Third, the Mulcahys lay great stress on the notion that incompatible pollen fails not because it is inhibited on the stigma or in the style, but because it grows too slowly to effect fertilisation before floral abscission. While floral abscission may be of some importance in this respect in species like Nicotiana alata or Lycopersicum peruvianum, it cannot be in others which retain their flowering parts long after pollination. Thus if floral abscission was as important as the Mulcahys suppose, it should be possible to obtain a full set of seed after self-pollination in those species which retain their gynoecia; that is, under experimental conditions, such species should be self-compatible. This consequence is not realised in practice. Thus in the species with which we are most familiar, Papaver rhoeas and Lolium perenne, the percentage of seed set after self pollination is, at best, very low despite the fact that individuals of both species retain their gynoecia until the end of the flowering season. The Mulcahys' model, therefore, cannot account for self-incompatibility in these species.

Lastly, the Mulcahys claim that their model can be extended to account for the pattern of pollinations observed in species with the multilocus systems found in the grasses, Beta vulgaris and Ranunculus acris; unfortunately, this is not true. Thus nine of the interactions shown in fig. 3 of their paper, though scoring more than -7 , which the Mulcahys choose on quite arbitrary grounds as being the threshold score between incompatibility ( $\leqq-8)$ and compatibility ( $\geqq-7)$, concern what in practice would be incompatible reactions; and one interaction, scoring -9 , would in practice be compatible. Similarly, three of the interactions in figure 4 , each scoring -9 and hence regarded as incompatible on the Mulcahys model, are again in fact compatible. It is clear, therefore, that their model is not capable of predicting what happens in practice. The reason for this is that the Mulcahys have overlooked the fact that the specificities in these species are the products of intergenic interaction. Thus four recognition substances are found in the stigmas of a diploid grass of genotype $S_{1} S_{2} Z_{1} Z_{2}$ corresponding to the set of four factorial combinations that can be formed between the two alleles present at each locus $\left(S_{1} Z_{1}, S_{1} Z_{2}, S_{2} Z_{1}\right.$, $S_{2} Z_{2}$ ). Pollen grains, being haploid, contain only one $S$ and one $Z$ allele, but because there are four combinations of the parental alleles, an $S_{1} S_{2} Z_{1} Z_{2}$ plant would produce four kinds of pollen (i.e. a pollen grain is either $S_{1} Z_{1}, S_{1} Z_{2}, S_{2} Z_{1}$ or $S_{2} Z_{2}$ ). Incompatibility occurs whenever a pollen grain alights on a stigma which contains the same $S-Z$ pair of alleles as the pollen. The same mechanism appears to operate in the four locus systems of $B$. vulgaris and $R$. acris except that plants of these species can form as many as sixteen different specificities in their stigmas and produce, correspondingly, up to sixteen types of pollen. But in all cases, these recognition substances are the products of intergenic interaction and cannot, therefore, be obtained by the summation of intra-genic (inter-allelic) interactions as on the Mulcahys' model. It follows, therefore, that their claim that their model provides an explanation of Larsen's $(1975,1977 a)$ results, as well as those of Nettancourt et al., (1971), cannot be sustained.

\section{DISCUSSION}

The Mulcahys' model cannot be regarded as a general model of gametophytic self-incompatibility for, as we have seen, it is not capable of providing an explanation for the compatibility relationships observed with multi-locus systems. Their model is, however, consistent with the empirical evidence concerning one-locus systems provided it is assumed that the constituent loci of the S-supergene are tightly linked and that one is prepared to accept the biochemical complexity involved in any multi-allelic system where the compatibility reaction is of the complementary type.

As regards the assumption of tight linkage between the constituent loci of the supergene, it is important to point out that the Mulcahys initially assume such linkage for explanatory purposes only. Thus later in their paper they state: "Perhaps, instead of being linked to each other as supergenes, these loci are randomly scattered throughout the entire genome". In view of this 
extraordinary statement, it is clear that their model cannot be regarded as consistent with the evidence concerning one-locus systems either. We have already mentioned one of the consequences of recombination between the loci of the supergene, namely, the generation of self-compatible plants. Furthermore, if the constituent loci of the Mulcahy supergene recombined at all frequently, full-sib families could contain more than two or four classes. In the course of our work with Papaver rhoeas (Campbell, 1977; O'Donnell, 1983), for example, we have examined over sixty full-sib families that were obtained by crossing unrelated plants raised from seed taken directly from natural populations of the species and have never found any which contained more than four legitimate genotypes. Indeed, if the Mulcahys' model were true, it would, of course, be impossible to discover any species with a one-locus system of self-incompatibility. It would also be impossible to map the S-gene; yet, as we have seen, there are no less than nine cases known of linkage between the $S$-gene and other genes in nine different species. The Mulcahys' model, therefore, fails to account for the empirical evidence concerning one-locus, multiallelic systems at the most elementary level.

There is, of course, little doubt that the S-gene is in fact a supergene, for otherwise it would not be possible to account for the occurrence of pollenpart and stylar-part mutations, those which affect only the pollen and the style respectively. Lewis (1960), for example, has suggested that the $S$-locus has a tripartite structure, one part determining specificity in the pollen and style, and the others activity in the pollen and in the style (see Nettancourt, 1977 for other models of the structure of the locus). The chief objection to the Mulcahys' model in this respect is that it is unnecessarily complex and that there is no evidence which suggests, so far as we are aware, that the $S$-locus consists of as many parts as there are $S$-alleles in the population.

This question of complexity also has important implications at the biochemical level for, as mentioned previously, the stigmas or styles of each individual would need to produce a substance that directly or consequentially could stimulate the growth of pollen carrying every allele in the population except those present in the individual itself. Yet the Mulcahys do not discuss this problem. The alternative view that the growth of incompatible pollen is positively inhibited offers a simple and parsimonious solution to this recognition problem. Furthermore, there is much evidence which supports this view. For example, in some species, such as Oenothera organensis (Emerson 1938, 1940), Papaver rhoeas (Lawrence, 1975; Lawrence, Afzal and Kenrick, 1978) and Lolium perenne (Cornish, Hayward and Lawrence, 1979), the growth of incompatible pollen is arrested on or in the stigma. Observations made under the microscope shows that the short, deformed tubes of incompatible pollen and often the pollen grains themselves become occluded with callose whose presence is revealed by the aniline-blue fluorochrome reaction (Linskens and Esser, 1957; Martin, 1959; Lalouette, 1967). The incompatibility reaction in another species of this kind, Secale cereale, takes place, apparently, within 2-10 minutes of the germination of the pollen (Heslop-Harrison, 1983). In Lycopersicum peruvianum, where the growth of incompatible pollen is arrested in the style, which is the more usual site of inhibition for species with a gametophytic system of self-incompatibility, the tips of incompatible pollen tubes burst when they have grown down one third of the style (Nettancourt et al., 1973). Evidence of this kind is obviously quite inconsistent with the notion that the growth of compatible pollen is stimulated; it can be explained only on the assumption that the growth of incompatible pollen is positively inhibited either in the stigma or the style.

Some of the most convincing evidence on this question comes from a recent investigation of autotetraploid ryegrass whose pollen, being diploid, carries two $S$ and two $Z$ alleles and hence can form as many as four $S-Z$ specificities when heteroallelic at both loci. Yet only one $S-Z$ pair in the pollen needs to be matched by the same pair in the stigma for incompatibility to occur despite the presence in the same pollen grain of three further $S-Z$ pairs which are not matched by those in the stigma (Fearon, Hayward and Lawrence, 1984). Since autotetraploids of ryegrass are as selfincompatible as their diploid progenitors, the nonmatched pairs of alleles cannot be producing substances which stimulate the growth of this pollen. Evidence of this kind, therefore, provides a critical test of the complementary hypothesis, which is clearly quite incapable of explaining this observation. Indeed, it is very hard to find any convincing evidence in the literature either of a genetical or physiological nature (see, for example, Nettancourt, 1977 on the former and Heslop-Harrison, 1983 , on the latter), which lends any support to the complementary hypothesis of the incompatibility reaction; on the contrary, the overwhelming weight of this evidence supports the oppositional hypothesis. We therefore feel that the Mulcahys attempt to resurrect the complementary hypothesis 
is perverse. Their perception of the evidence is quixotic and their model ill-founded. It follows, therefore, that, in our view, their claim to have put forward a new model of gametophytic self-incompatibility which is consistent with the empirical evidence cannot be sustained.

\section{REFERENCES}

BATESON, W. AND GREGORY, R. P. 1905. On the inheritance of heterostylism in Primula. Proc. R. Soc. Lond. B., 76, 581-586.

BRIEGER, F. G. AND MANGELSDORF, A. J. 1926. Linkage between a flower color factor and self-sterility factors. Proc. Nat. Acad. Sci. (Wash)., 12, 248-255.

CAMPBELL, J. M. 1977. Population genetics of self-incompatibility in Papaver rhoeas L. Ph.D. thesis, University of Birmingham.

CAMPBELL, J. M. AND LAWRENCE, M. J. $1981 a$. The population genetics of the self-incompatibility polymorphism in Papaver rhoeas. I. The number and distribution of $S$-alleles in families from three localities. Heredity, 46, 69-79.

CAMPBELL, J. M. AND LAWRENCE, M. J. $1981 b$. The population genetics of the self-incompatibility polymorphism in Papaver rhoeas. II. The number and frequency of $S$-alleles in a natural population (R106). Heredity, 46, 81-90.

CORNISH, M. A., HAYWARD, M. D. AND LAWRENCE, M. J. 1979. Self-incompatibility in ryegrass. I. Genetic control in diploid Lolium perenne L. Heredity, 43, 95-106.

CORNISH, M. A., HAYWARD, M. D. AND LAWRENCE, M. J. 1980. Self-incompatibility in ryegrass. III. The joint segregation of $S$ and PGI-2 in Lolium perenne. Heredity, 44, 55-62.

DENWARD, T. The function of the incompatibility alleles in red clover (Triolium pratense L.). Hereditas, 49, 189-334.

EAST, E. M. AND MANGELSDORF, A. J. 1925. A new interpretation of the hereditary behaviour of self-sterile plants. Proc. Nat. Acad. Sci. (Wash.), 11, 166-171.

EMERSON, S. 1938. The genetics of self-incompatibility in Oenothera organensis. Genetics, 23, 190-202.

EMERSON, S. 1939. A preliminary survey of the Oenothera organensis population. Genetics, 24, 524-537.

EMERSON, S. 1940. Growth of incompatible pollen tubes in Oenothera organensis. Bot. Gaz., 101, 890-911.

EMERSON, S. 1941. Linkage relationships of two gametophytic characters in Oenothera organensis. Genetics, 26, 469-473.

ESSER, K. 1953. Genomverdopplung und Pollenschanchwachtum bei Heterostylen. Z. indukt. Abstamm.-u. Vererblehre, $85,28-50$.

FEARON, C. H., HAYWARD, M. D. AND LAWRENCE, M. J. 1983. Self-incompatibility in ryegrass. V. Genetic control, linkage and seed-set in diploid Lolium multiflorum Lam. Heredity, $50,34-45$.

FEARON, C. H., HAYWARD, M. D. AND LAWRENCE, M. J. 1984. Self-incompatibility in ryegrass. IX. Cross-compatibility and seed-set in autotetraploid Lolium perenne L. Heredity, $53,423-434$.

FISHER, R. A. AND MATHER, K. 1943. The inheritance of style length in Lythrum salicaria. Ann. Engenics 12, 1-23.

GASTEL, A. J. G. VAN AND NETTANCOURT, D. DE. 1975. The generation of new incompatibility alleles. Incompatibility Newsletter, 6, 66-69.

GERSTEL, D. V. 1950. Self-incompatibility studies in Guayule. II. Inheritance. Genetics, 35, 482-506.
HAYMAN, D. C. 1956. The genetical control of incompatibility in Phalaris coerulescsns Dest. Aust. J. Biol. Sci., 9, 321-331.

HESLOP-HARRISON, J. 1983. Self-incompatibility: phenomenology and physiology. Proc. R. Soc. Lond. B., 218, $371-$ 395.

HOFFMAN, F. AND LENZEL, G. 1981. Self-compatibility in microspore-derived doubled-haploid rye lines and single grain selection for alkylresorcinol content. Theor. Appl. Genet., 60, 129-133.

HUGHES, M. B. AND BABCOCK, E. B. 1950 . Self-incompatibility in Crepis foetida (L). subsp. rhoeadifolia (Bieb) Schinz et Keller. Genetics, 35, 570-588.

LABROCHE, PH., POIRIER-HAMON, S. AND PERNES, J. 1983. Inheritance of leaf peroxidase isozymes in Nicotiana alata and linkage with the $S$-incompatibility locus. Theor. Appl. Genet., 65, 163-170.

LALOUETTE, J. A. 1967. Growth of pollen tubes exhibited by callose fluorochrome reaction. Grana palynol., 7, 601-603.

LARSEN, K. 1975. Correlation between the quadruple heterozygous $S$-genotype $S_{\mathrm{a}}^{1 \cdot 2} S_{\mathrm{b}}^{3 \cdot 4} S_{\mathrm{c}}^{5 \cdot 6} S_{\mathrm{d}}^{7 \cdot 8}$ and pseudocompatibility in Beta vulgaris L. Incompatibility Newsletter, $5,85-88$.

LARSEN, K. 1977 a. Pseudo-compatibility in Beta vulgaris L. A quantitative character, dependent on the degree of $S$-gene heterozygosity. Incompatibility Newsletter 8, 48-51.

LARSEN, K. 1977b. Self-incompatibility in Beta vulgaris L. I. Four gametophytic, complementary $S$-loci in sugar beet. Hereditas, 85, 227-248.

LARSEN, K. 1978a. Four genes in one linkage group in Beta vulgaris L. Incompatibility Newletter, 9, 78-82.

LARSEN, K. $1978 b$. Quantitative modification of the compatibility reaction in Beeta vulgaris L. Incompatibility Newsletter, 9, 83-86.

LARSEN, K. 1978 c. Oligoallelism in the multigenic incompatibility system of Beta vulgaris L. Incompatibility Newletter, 10, 23-28.

LAWRENCE, M. J. 1975. The genetics of self-incompatibility in Papaver rhoeas. Proc. R. Soc. Lond. B., 188, 275-285.

LAWRENCE, M. J., AFZAL, M. AND KENRICK, J. 1978. The genetical control of self-incompatibility in Papaver rhoeas. Heredity, 40, 239-252.

LAWRENCE, M. J. AND O'DONNELL, S. 1981. The population genetics of the self-incompatibility polymorphism in Papaver rhoeas. III. The number and freqeuncy of $S$-alleles in two further natural populations (R102 and R104). Heredity, 46, 53-61.

Levin, A. A., RItTer, K. AND Ellstrand, N. C. 1979. Protein polymorphism in the narrow endemic Oenothera organensis. Evolution, 33, 534-542.

LEWIS, D. 1943. The physiology of incompatibility in plants. II. Linum grandiflorum. Ann. Botany. N.S., 7, 115-122.

LEWIS, D. 1948. Structure of the incompatibility gene. I. Spontaneous mutation rate. Heredity, 2, 219-236.

LEWIS, D. 1949. Structure of the incompatibility gene. II. Induced mutation rate. Heredity, 3, 339-355.

LEWIS, D. 1951. Structure of the incompatibility gene. III. Types of spontaneous and induced mutation. Heredity, 5, 399414.

LEWIS, D. 1954. Comparative incompatibility in angiosperms and fungi. Adv. in Genetics, 6, 235-285.

LEWIS, D. 1960. Genetic control of specificity and activity of the $S$ antigen in plants. Proc. Roy. Soc. Lond. B., 15l, 468-477.

LINSKENS, H. F. AND ESSER, K. L. 1957. Uber eine spezifische Anfarbung der Pollenschlauche im Griffel und die Zahl der Kallosepfropfen nach Selbstdung und Fremdung. Naturwis, 44, 1-2. 
LUNDQVIST, A. 1956. Self-incompatibility in rye. I. Genetic control in the diploid. Hereditas, 42, 293-348.

LUNDQVIST, A. 1958. Self-incompatibility in rye. IV. Factors related to self-seeding. Hereditas, 44, 193-256.

MARTIN, F. W. 1.959. Staining and observing pollen tubes in the style by means of fluorescence. Stain Technology, 34, $125-128$

MULCAHY, D. L. AND MULCAHY: G. B. 1983. Gametophytic self-incompatibility reexamined. Science, 220, 1247-1251.

NETTANCOURT, D. DE. 1977. Incompatibility in Angiosperms. Springer Verlag, Berlin.

NETTANCOURT, D. DE, ECOCHARD, R., PIERQUIN, M. D. G., DRIFT, T. VAN DE ANI) WESTERHOF, M. 1971. The generation of new S-alleles at the incompatibility locus of Lycopersicum peruvianum Mill. Theor. Appl. Genet., 41, $120-129$

NETTANCOURT, D. DE. DEVREUX, M., BOZZINI, A., CREŞTI, M., PACINI, E. AND SARFATTI, G. 1973. Ultrastructural aspects of self-incompatibility mechanism in Lycopersicum peruvianum Mill. J. Cell Sci., 12, 403.419.

NETTANCOURT; D. DE, DEVREUX, M., CARLUCCIO, F., LANERI. V., CRESTI, M. PACINI, E., SARFATTI, G. AND GASTEL, A. J. G. VAN. 1975. Facts and hypotheses on the origin of $S$ mutations and on the function of the $S$ gene in Nicotiana alata and Lycopersicum peruvianum. Proc. Roy. Soc. Lond. B., 188, 233.375.

O'DONNELL, S. 1983. Population genetics of self-incompatibility in Papaver rhoeas L. Ph.D. thesis, University of Birmingham.

OSTERBYE, U. 1975. Self-incompatibility in Rannuculus acris L. I. Genetic interpretation and evolutionary aspects. Hereditas, 80, 91-112.

PRELL, H. 1921. Das Problem der Unbefruchtbarkeit. Naturw. Wschr. N.F., 20, 440-446.

SREE RAMULU, K. $1982 a$. Failure of obligate inbreeding to produce new $S$-alleles in Lycopersicum peruvianum Mill. Incompatibility Newsletter, 14, 103-110.

SREE RAMULU, K. $1982 \mathrm{~b}$. Genetic instability at the $S$-locus of Lycopersicum peruvianum plants regenerated from in vitro cuiture of anthers: generation of new $S$-specificities and $S$-allele reversions. Heredity, 49, 319-330.

THOMPSON, K. F. AND TAYLOR, J. P. 1965. Identical $S$ alleles in different botanical varieties of Brassica oleracea. Nature, 208, 306-307.

WRIGHT, S. 1939. The distribution of self-sterility alleles in population. Genetics, 24, 538-552. 